Portland State University

PDXScholar

Center for Urban Studies Publications and

Reports

Center for Urban Studies

3-1991

\title{
A Ranking of U.S. Graduate Programs in Urban Studies and Urban Affairs
}

James G. Strathman

Portland State University

Follow this and additional works at: https://pdxscholar.library.pdx.edu/cus_pubs

Part of the Educational Assessment, Evaluation, and Research Commons, and the Urban Studies and Planning Commons

Let us know how access to this document benefits you.

\section{Citation Details}

Strathman, James G., "A Ranking of U.S. Graduate Programs in Urban Studies and Urban Affairs" (1991). Center for Urban Studies Publications and Reports. 150.

https://pdxscholar.library.pdx.edu/cus_pubs/150

This Report is brought to you for free and open access. It has been accepted for inclusion in Center for Urban Studies Publications and Reports by an authorized administrator of PDXScholar. Please contact us if we can make this document more accessible: pdxscholar@pdx.edu. 


\section{A RANKING OF U.S. GRADUATE PROGRAMS IN URBAN STUDIES AND URBAN AFFAIRS}

by

James G. Strathman

March 1991

Center for Urban Studies

School of Urban and Public Affairs

Portland State University

Portland, OR 97207-0751

(503) 725-4020

(503) 725-5199 FAX

http://www.upa.pdx.edu/centers.html\#CUS

PORTLAND STATE UNIVERSITY SUPPORTS EQUAL OPPORTUNITY IN ADMISSIONS, EDUCATION, AND USE OF FACILITIES, PROHIBITING DISCRIMINATION IN THOSE AREAS BASED ON RACE, SEX, SEXUAL ORIENTANION, COLOR, RELIGION,
NATIONAL ORIGIN, HANDICAP, OR AGE. THIS POLICY IS IN ACCORD WITH STATE AND FEDERAL LAW. 


\title{
A Ranking of U.S. Graduate Programs in Urban Studies and Urban Affairs
}

\begin{abstract}
$\underline{\text { Abstract }}$
A ranking of 33 Urban Studies and Urban Affairs graduate programs in the U.S. is developed from peer ratings obtained in a program survey and from citation activity reported in the Social Sciences Citation Index over the 1986-89 period. In addition, a breakdown of citations by broadly defined subject areas is presented. The survey revealed a difference between $\mathrm{Ph} . \mathrm{D}$. and MUS/MA programs in the perceived relative importance of peer evaluation and citations as rating criteria. The survey results also indicate that the degree of familiarity with other programs is lower than what has been observed in most social science disciplines.
\end{abstract}

\section{Introduction}

This paper presents rankings of graduate programs in Urban Studies and Urban Affairs (US/UA) based on citations of published faculty research and subjective ratings of programs by their peers at other institutions. A composite rating integrating the two approaches is also derived using relative weights obtained from a program survey. The results provide an update of the rankings presented by Bingham, Henry and Blair (1981), hereafter referred to as BHB. In addition, a breakdown of citations by general subject area is presented in order to provide a tentative picture of the structure of scholarship in the discipline.

In recent years there has been considerable interest in ranking programs in the social sciences. A principal objective behind these efforts is to provide something akin to an "annual report" by which faculty, administrators, students considering alternative graduate programs, and various other relevant constituents can gain an appraisal of academic performance. But one should be careful not to view the annual report analogy too literally. In contrast with the hypothetical firm, academic "output" is multi-dimensional and comprised of complex quantity and quality-related attributes. Attempts to specify, measure 
or place a value on this output, however comprehensive and rigorous, still represent fairly rough approximations. Indeed, one can argue that this is particularly the case in US/UA because of its multi-disciplinary focus.

While recognizing that no ranking framework fully captures the contributions programs make to their students and the urban and academic communities, it is apparent that some designs are better suited to the task than others. Alternative approaches are thus reviewed in the next section, and a methodology compatible with the characteristics of the discipline is identified. The research design is then outlined, followed by a presentation of the results. The paper concludes with a brief discussion of the findings.

\section{The Pros and Cons of Alternative Rating Methods}

Rating methods can be generally distinguished by their basis in either subjective or objective measurement. A subjective approach seeks to establish the relative standing of a program through evaluation by peer faculty at other institutions. This approach is best represented by the study of doctorate programs in the U.S. sponsored by the Conference Board of Associated Research Councils (Jones et al, 1982). Alternatively, the objective approach provides program rankings derived from counts of either faculty publications (Robey, 1979; Kau and Johnson, 1983) or citations of the faculty's published work (Roche and Smith, 1978; Davis and Papanek, 1984; Turner and Meyer, 1985; Blair et al, 1986). The BHB study relied on a combination of peer ratings, a count of books published, and citation counts. Multiple indexes have also been employed by Morrill (1980), Jones et al (1982), and Laband(1985).

The major advantage of peer ratings is that they are capable of encompassing the numerous intangible factors that are generally acknowledged to be important in a graduate program, but are virtually impossible to quantify. In the Conference Board study, for example, evaluators were instructed to reflect in their ratings a program's overall scholarly quality, how effectively it educates its students, and how overall program quality had changed in recent years. Critics of this approach argue that it is not clear what the peer 
ratings actually reflect. The level of information upon which the rating is based is unknown. As BHB noted, when information is limited the rating may be more reflective of the reviewer's overall assessment of the institution rather than the program. Turner and Meyer (1985) claim that the ratings are more likely to reflect the perceived quality of the program's more prominent scholars rather than the overall faculty. They also charge that its application is more difficult in multi-disciplinary environments because reviewers are prone to be swayed by their own field of study and are less aware of activity in other subfields. Whether the peer ratings reflect perceptions of the present status of a program or its historic image is also unknown. If the latter, a program "on the rise" is likely to be underrated, while a traditionally prominent program now "resting on its laurels" is more likely to be over-rated.

The uncertainties associated with peer-based ratings probably account for the greater confidence generally expressed with publication and citation counts. Publication counts provide a direct measure of the quantity of scholarly output. However, a major early criticism of this approach was that it treated all publications equally; an article in a discipline's "flagship" journal was treated as equivalent to one appearing in a less prestigious source. To account for this, studies began to apply weights to the journals reflecting their relative importance (Glenn, 1971; Robey, 1979). Regarding books, this type of modification has apparently been considered unworkable. Rankings based on publication counts also ignore the problem of faculty mobility (i.e., the listed institutional affiliation at the time of publication may be different from the current affiliation of the author).

Generally, the usefulness of publication counts is limited to disciplines with a wellestablished paradigm and a clear hierarchy of journals. Multi-disciplinary fields lack both of these characteristics; subfields typically predominate and the relevant journals tend to be defined by field specialities. For these reasons, it is hard to imagine an ordering of journals in US/UA that would meet with general satisfaction. 
One innovative application of publication counts in a multi-disciplinary environment is the study of Regional Science by Kau and Johnson (1983). This field has a wellestablished paradigm, an active professional association, and a clearly identifiable set of core journals. What is relatively lacking, however, are degree-offering programs. Kau and Johnson used publication counts (i.e., page equivalents) from the major Regional Science journals to identify and rank the individuals and various institutions whose research was contributing to the field.

In contrast with publication counts, citations provide a measure of research productivity that reflects the quality of scholarly contributions. Citations reflect the extent to which other researchers have found a contribution to be significant to their own work. The difficulties associated with a priori evaluation of the relative importance of various journals are avoided, and the question of the relative impacts among books (as well as between book and journal publications) is resolved. With the Social Sciences Citation Index (SSCI), citations are drawn from a wide variety of sources (about 2,500 journals in 1989), ensuring near-complete coverage of the refereed outlets in the social sciences.

A number of potential substantive and clerical problems are encountered with citation counts (Cole and Cole, 1971; Stigler and Friedland, 1975; Turner and Meyer, 1985). First, given the time lag between submission, publication, and subsequent citation of research, junior faculty are at a disadvantage against more senior faculty with a sustained record. Second, scholars contributing to subfields with many participants (e.g., urban economics, urban sociology) may be more heavily cited than others in subfields with relatively few participants (e.g., urban history), even though their contributions might be judged to be of equal quality. Third, citations are reported for first authors only; faculty who have contributed disproportionately as secondary authors will be under-recognized. Also, citations of edited works are usually listed under the first editor; faculty who are more active contributors to volumes edited by others are thus likely to go unrecognized. Fourth, literature reviews tend to siphon off citations from the seminal contributions they 
cover. Lastly, citations can be "parochial;" authors disproportionately cite their colleagues and graduate program mentors. Whether this is due to greater familiarity with the research undertaken in one's program, or the program's effectiveness in instilling its perspective in its graduates, the effect of parochialism is to shift the citation advantage toward Ph.D. programs and to favor larger Ph.D. producers over smaller ones.

The potential for "measurement error" should not be dismissed lightly, particularly when the citations relate to multi-disciplinary environments. Citations are reported literally as they appear in the covered article's references. Citations of publications by Donald Schon, for example, are listed under the headings "Schon," "D. Schon," "D. A. Schon," as well as a variety of mis-spelled alternatives. Citations of authors with the same names and initials are reported under the same heading. Distinctions between authors can be made by checking cited works in the Social Sciences Source Index (SSSI), which reports the author's institutional affiliation, or the Cumulative Book Index. If the cited work is not listed in the SSSI, or if the author has moved, a clear basis for distinguishing among similarly-named authors may not be possible. Frequently, the citation itself suggests whether the author is linked to US/UA or an unrelated discipline, though not always (e.g., the citations of both Lance and Lester Taylor are listed together, and both have contributed extensively to journals in Economics). Sifting out the pertinent citations of US/UA authors with fairly common surnames can be both time consuming and confounding. Finally, a mid-career marriage can conceal citations if there is a change in surname.

The factors described above constitute errors of unknown magnitude. A key concern is whether these errors systematically work for or against particular US/UA programs. Programs with a history of attracting highly productive junior faculty and subsequently losing them to more lucrative opportunities can be characterized as the most likely candidates to be "short-changed" by citation counts. Alternatively, programs who make it a practice to hire distinguished senior scholars may be disproportionately favored for contributions that originated elsewhere years earlier. 
None of the rating methods discussed above provides a fully satisfactory assessment of urban public service, applied research, and the quality of programs in terms of enhancing student development. In contrast with the Conference Board effort, several studies (Laband, 1985; Knudsen and Vaughn, 1969) have attempted to address the educational quality issue by including citations of the programs' graduates, but this raises several problems. First, a small percentage of graduates move into academic appointments (e.g., see Carson and Navarro, 1988). Second, this measure of research performance, along with more subjective appraisals of program educational quality, are more reflective of the quality of students that are admitted to a program rather than the effect that a program has had on its students (Gilmore, 1990).

Public service and applied research are important elements of the mission of most US/UA programs. Unfortunately, very little is known about these activities outside the metropolitan areas where they occur. Attempts to include these activities as a basis for peer evaluation would subject reviewers to greater uncertainty and would decrease the likelihood of their response. Or, worse still, with greater uncertainty peer evaluations might be more subject to the institutional "halo effect" on program ratings. While admittedly important, public service, applied research, and student development issues are simply beyond the capabilities of the alternative rating methodologies.

Given the characteristics of the discipline in relation to the strengths and weaknesses of the alternative rating methods, a combination of the peer evaluation and citation approaches seems appropriate. Publication counts are ruled out because of the diversity of journals that serve as outlets for US/UA research, as well as the virtual impossibility of establishing a weighting system for these journals. Simple publication counts would fail to account for differences in quality - nearly $75 \%$ of all social science journal articles covered by the SSCI go uncited (Hamilton, 1991). Citation counts by themselves provide a too-narrowly focused assessment of graduate programs. Thus a combination of the citation count and peer evaluation approaches has the potential of 
providing a more comprehensive assessment, as well as one that is sensitive to the quality of research contributions.

The BHB study employed citation counts and peer evaluations; however, it also incorporated a count of books published. The inclusion of this third indicator was based on the contention that multi-disciplinary endeavors tend to rely more heavily on books as a medium of scholarly communication. While this may be so, supplementing citations with a count of books and not journal articles means that books are allowed to contribute to program ratings both quantitatively and qualitatively, while journal articles are allowed to contribute on a qualitative basis only. This clearly tilts the overall assessment in favor of programs that are disproportionately engaged in book publishing. A fair balance between book and journal publication counts would require either inclusion or exclusion of both. A complete tally of journal publications would depend on obtaining the CV's of the faculty of all US/UA programs in the study. Unanimous response to such a request can hardly be anticipated, and it was thus decided to include neither book nor journal article counts. While book publishing requires a considerably greater time investment, it should also be noted that books are, on average, more heavily cited than journal articles (Roche and Smith, 1978).

Research Design

Locating US/UA graduate programs remains a problem, although the BHB study provides a useful starting point and still-relevant selection criteria. These criteria include a) granting the Ph.D. in US/UA, the MUS, MUA, or a multi-disciplinary equivalent; and b) the existence of an independent core faculty. Programs offering only urban-related professional degrees (e.g., planning or public administration) or degrees in the social sciences with urban field specializations were not included.

To identify current programs the original list of 31 programs developed by BHB was checked against the Urban Studies listing reported in the 1990 Peterson's Guide to Graduate Programs in the Humanities and Social Sciences, and the list of institutional 
members of the Urban Affairs Association (UAA). The catalogues of programs listed in the BHB study but not in the other sources were reviewed to determine whether a change in status had occurred. In instances where the status of a program was unclear, direct contact was made. Eight programs from the BHB study were identified as no longer offering US/UA graduate degrees: Alabama-Birmingham, Colorado-Denver, Howard, LoyolaChicago, Occidental, Pittsburgh, Southern California, and Wichita State. Programs listed in the Peterson's guide or by the UAA but not contained in the BHB study were then similarly evaluated. Ten "new" graduate programs were identified: Alabama A\&M, Georgia State, Michigan State, Montclair State, Northeastern Illinois, Queens, Tufts, Louisville, District of Columbia, and Wright State. Two of these programs (Alabama A\&M and Northeastern Illinois) apparently would have satisfied the criteria for inclusion in the earlier study. Thus while there has been substantial turnover in the intervening decade, the number of programs remains essentially unchanged.

As in the previous study some judgement was required in determining which programs to include. Wright State was authorized in 1989 to expand to the graduate level, but had not yet admitted students. The program at Michigan State offers graduate degrees in Urban Studies in collaboration with a number of other programs; although it does not offer a free-standing degree, it does have a core faculty and curriculum. Both of these programs were included. The inclusion of the Maxwell School at Syracuse was again limited to the Metropolitan Studies program. Conversely, the Graduate School and University Center of CUNY has Ph.D. and MA offerings in Urban Studies, but was excluded because it relies heavily on the participation of Hunter and Queens (which are already included).

A survey was mailed to US/UA program directors in order to recover information on three subjects. First, the directors were asked to identify their core faculty for the 198990 academic year. They were asked to exclude those faculty with visiting, adjunct, or emeritus status. They were asked to report budgeted FTE for core faculty as an indicator of 
their participation in the program. This information was requested in recognition of the likelihood that US/UA, because of its multi-disciplinary orientation and relatively recent emergence as a field of study, would tend to rely more heavily on joint appointments with other social science programs. The directors were also instructed to include individuals whose contribution to the program (e.g., through teaching, research, service, and participation on thesis committees) was significant, but whose FTE was covered by a separate administrative or research unit. Should all programs respond to the survey, the FTE information could be used to apportion the citations of faculty with joint appointments. With less than unanimous response, a separate analysis of the correspondence between FTE-weighted and nominal citation tallies could still be undertaken.

The second subject addressed in the survey concerned the peer ratings of US/UA programs at other institutions. The directors were asked to rate the overall quality of programs on a scale of 0 to 10 . They were asked to take into consideration the three dimensions employed in the Conference Board study, defined as follows: a) the faculty's "scholarly competence and achievements;" b) the effectiveness of the program in educating its students, taking into account the accessibility of faculty, and the quality of the curriculum, facilities, students, and graduates; and c) the change in the overall quality of the program over the past five years. The directors were instructed to withhold ratings for programs about which they did not have a general impression regarding these factors. For obvious reasons, they were instructed not to rate their own program.

Third, the program directors were asked to record on a scale of 0 to 100 the relative percentage weights they felt should be given to peer ratings and citations as component elements of a composite rating. Knowing these relative weights would permit more than a simple aggregation of the two measures. It would also be possible to determine whether their relative importance is sensitive to program characteristics. For example, Blair et al (1986) stated that Masters programs face a different set of performance incentives, have heavier teaching loads, have access to fewer institutional resources, and lack graduate 
research assistants. Given these conditions, they can be expected to place less emphasis on research oriented rating criteria than would $\mathrm{Ph} . \mathrm{D}$. programs. The survey responses on the relative weight for citation counts provide a simple basis for testing this hypothesis.

Citations of contributions by US/UA faculty were tabulated for the years 19861989. Several of the conventions employed by Turner and Meyer (1985) were adopted. Self-citations, citations by anonymous sources, and citations of unpublished work (e.g., dissertations, reports, working papers) were excluded. Turner and Meyer also excluded citations from book reviews, but it was decided to include them in this study in recognition of BHB's claim regarding the importance of books in US/UA. The SSCI also reports the number of citations an author received in the Science Citation Index (SCI), but does not report the name of the citing author or the source of the citation. These references to citations in the SCI (relatively few in number) were included.

\section{$\underline{\text { Results }}$}

Twenty-five of the 33 graduate programs (76\%) responded to the peer evaluation survey. Two of the respondents did not provide program ratings, and one did not specify relative weights for the peer evaluation and citation criteria. Non-responding programs were contacted by telephone to determine whether the faculty listed in their catalogues complied with the criteria employed in the survey.

Mean program ratings tabulated from the peer survey are reported in Table 1. Delaware and MIT are clearly distinguishable at the top. A second distinct cluster comprised of Portland State, Texas-Arlington, Syracuse, Louisville, Carnegie Mellon, Cleveland State, the New School, and Tufts round out the top ten. A third cluster headed by Wisconsin-Milwaukee runs from 11th through 15th place, followed by a gradual tapering off among the remaining 18 programs. The programs that have that have emerged since the BHB study are led by Louisville (6th), Tufts (10th), and Michigan State (12th). It is noteworthy that the top eight rated programs offer the Ph.D.

(Table 1 about here) 
A familiarity score - the percentage of the survey respondents who felt they knew enough about the scholastic qualities, educational aspects, and recent directions of programs to rate them - is also reported in Table 1. An association between program rating and familiarity is clearly evident $(\mathrm{r}=.77 ; \mathrm{p}<.001)$. The exceptions to this pattern include three programs that were rated relatively highly by a relative few respondents: Tufts (which was known by only a third of the respondents), St Louis (known by 39\%), and Northeastern Illinois (known by 22\%).

On average, survey respondents whose program offered the Ph.D. tended to be familiar with a larger percentage of the other programs (53\% versus $39 \%$ by MUS/MUA respondents), but the significance of this difference was weak $(\mathrm{p}<.15)$. Alternatively, Ph.D. programs were clearly more familiar to the respondents than were the MUS/MUA programs $(59 \%$ versus $38 \% ; \mathrm{p}<.003)$. The greater familiarity of the respondents with the Ph.D. programs may be generally attributed to their size and curriculum, their higher visibility as publishers and conference participants, and the relative longevity of their programs.

The Conference Board study (Jones et al, 1982), employed the same basic rating criteria as this study's peer survey; thus we can compare the level of familiarity of the US/UA Ph.D. programs with their social science disciplinary counterparts. For social science disciplines covered in the Conference Board study, program familiarity averaged $68 \%$. Only Psychology, whose Ph.D. programs were recognized by 54\% of the peer evaluators, exhibited a lower level of familiarity than the US/UA Ph.D. programs. One would expect that the relatively small size of the discipline would have resulted in greater familiarity of US/UA Ph.D. programs. For example, Geography, which conferred by far the fewest doctorates, was the predominant familiarity leader (83\%) in the Conference Board study.

Several considerations are probably important in explaining the relatively low level of familiarity of US/UA. programs. As a multi-disciplinary enterprise, US/UA tends to be 
defined more by its subfields than by a central paradigm. Faculty engaged in these subfields are still primarily drawn from allied social science disciplines, to which their allegiance can be expected to remain strong. The Ph.D. programs in US/UA also tend to vary in terms of the relative emphasis they devote to the various subfields; Carnegie Mellon and Louisville, for example, are very familiar to programs emphasizing criminology, but probably less familiar to programs emphasizing urban design and historic preservation. The fact that US/UA is still in its infancy in comparison with the other Social Science disciplines should also not be overlooked in evaluating familiarity.

Total and per capita citations are reported in Table 2. According to Davis and Papanek (1984), total citations are a reflection of the scope and depth of scholarly recognition, while the per capita measure is a better indicator of average strength. The count of total citations places both MIT and Carnegie Mellon well ahead of the other programs. Syracuse, with about half the citations of MIT, places third and WisconsinMilwaukee, with about half the citations of Syracuse, places fourth. A gradual tapering off is then observed from Cleveland State on down.

(Table 2 about here)

The per capita citations adjust for variations in faculty size. MIT, Carnegie Mellon, Syracuse, and Wisconsin-Milwaukee again top the list, with Syracuse closing the gap between itself and the top two programs. The per capita measure also highlights a number of smaller programs with relatively productive faculty, including Tufts (tied at 9 th in total citations to 4 th in per capita citations), Queens (12th to 7 th), Akron (14th to 9th), and Texas-Arlington (19th to 10 th).

Table 2 also provides an indicator of the extent to which a program's total citations are concentrated among a relative few highly productive faculty. This measure of concentration was suggested by Turner and Meyer (1987) and is defined as the smallest percentage of a program's faculty accounting for $50 \%$ of its citations. It was found to be very weakly correlated with total citations $(\mathrm{r}=-.303)$ and per capita citations $(\mathrm{r}=-.232)$, 
and in both cases was not statistically significant. This is consistent with BHB's finding that dropping the citations of "superstars" from the programs had little effect on the rankings.

From the 25 survey responses we can also determine whether joint appointments have a systematic effect on the pattern of total and per capita citations. This might occur if some programs tended to provide joint appointments to heavily cited individuals in order to increase their visibility, while other programs provided them to "ordinary" faculty in order to meet their curricular needs. The average budgeted FTE per faculty member among the respondents was .79 , indicating that joint appointments are fairly common. The survey data was used to generate a second list of FTE-weighted total and per capita citations. The correlations between the FTE-weighted citation measures and their nominal counterparts were very high ( .981 for total citations and .904 for per capita citations) and significant (p $<.0001$ ), which suggests that accounting for the effects of joint appointments would not affect the citation ratings reported here.

A principal issue in constructing a composite rating of programs is establishing the relative importance of peer ratings and citations. The overall mean peer/citation weights supplied by the survey were $.48 / .52$. As expected, however, Ph.D. programs weighted citations higher than did the MUS/MUA programs (.61 versus .44), and this difference was significant $(\mathrm{p}<.05)$. As a result, composite ratings are provided below based first on the overall mean weights (Table 3), and then on weights linked to program degree status (Table 4).

\section{(Table 3 about here)}

Given that the peer ratings and citation measures employ different scales, a conversion to z-scores is required for aggregation. These scores are presented in the first three columns of Table 3. The relative weights are then used to construct two composite ratings, the first combining peer ratings and total citations, and the second combining peer ratings and per capita citations. Both composite measures identify the same top five 
programs: MIT, Carnegie Mellon, Syracuse, Delaware, and Portland State. The first three of these programs represent a distinct cluster, particularly with the second composite measure, while the latter two programs are distinct from another cluster that runs from 6 th through 10th. Ranking the second group of five programs clearly depends on one's choice of scale. Tufts ranks 10 th on the first composite measure and 6th on the second, switching places with Wisconsin-Milwaukee. To a lesser extent, the same situation pertains with Cleveland State, Texas-Arlington, and Louisville.

Giving greater emphasis to citations has no effect on the ranking of Ph.D. programs based on the first composite measure (see Table 4). With the second composite measure Portland State and Delaware switch places at 4th and 5th, while Wisconsin-Milwaukee moves up two places to 6 th.

\section{(Table 4 about here)}

The rankings of the MUS/MUA programs are also little affected by increasing the relative importance of the peer ratings. Tufts is clearly on top, followed by a cluster comprised of Temple, the New School, Virginia Tech, and New Orleans. A second cluster is evident in the 6th through 10th position (St Louis, Georgia State, Northeastern Illinois, Maryland, and Hunter).

Inspection of the peer rating and citation z-scores suggests a roughly parallel pattern. The correlations between peer ratings and total and per capita citations are .477 ( $p$ $<.15)$ and $.502(\mathrm{p}<.009)$, respectively. Total and per capita citations are correlated at $.965(\mathrm{p}<.0001)$. The peer/citation correlations are slightly higher than what BHB observed in their earlier study. Nevertheless, it is evident that the peer ratings are reflecting judgements that take factors in addition to scholarly recognition into account. Given that the more favorably endowed programs fared relatively better in the citation counts than they did in the peer evaluation, one can safely rule out the institutional "halo effect" as a distorting factor in the peer ratings. In short, it appears that the peer ratings reflect what 
they were intended to reflect, and that the citation counts complemented rather than duplicated them.

Apart from the issue of the relative standing of Urban Studies and Urban Affairs programs is the question of the focus of scholarly activity. It has been contended that the discipline has moved away from its 1960 's focus on the "sociology of space" to a new emphasis on applied research concerned more with economic and fiscal issues (Raymond, 1989). Schmandt and Wendel's (1988) findings lend some support to this view, but their content analysis was limited to articles published in the Urban Affairs Quarterly. As Burby and Kaiser (1988) noted, urban scholars publish in a wide variety of journals; limiting one's attention to any one of them may yield results that are not generally representative. The citation patterns of US/UA faculty offer an advantage as an alternative because they avoid the problem of defining a representative collection of journals and they also better reflect the impacts that contributions to various fields of research have had within and beyond the discipline.

In order to develop a breakdown of citations by area it is first necessary to define the principal subject focus of US/UA faculty research. Clearly, a number of individuals can be considered contributors in several subject areas, and "pigeon-holing" them in this way can distort the pattern. Also, it is difficult to clearly establish the focus of faculty who receive relatively few citations. In reviewing the citations of US/UA faculty, it was evident that those who had been cited more frequently had developed a more apparent subject orientation in their research, and that a threshold of about 25 citations (1986-89) distinguished this group. Limiting our attention to these "vanguard scholars" yields a group of 66 individuals (16.4\% of all graduate program faculty) whose 5,211 citations account for $76 \%$ of the total (see the Appendix for a list of these individuals).

The percentage breakdown of the citations of the most cited US/UA faculty by the principal subject area of their research is presented in Table 5. Research focusing on urban and regional economics and economic development captured the largest share of citations 
(31\%), followed by contributions in the area of social analysis $(20 \%)$. The areas of criminology, urban politics, and public finance each account for $12-13 \%$ of the citations, with urbanization, planning and environmental analysis (8\%) and urban history (4\%) rounding out the list. It should be noted that citations of planning-related research are in part an artifact of the inclusion of eight graduate programs that offer degrees in both US/UA and planning.

Although the subject areas here are defined somewhat differently than those used by Schmandt and Wendel (1988), this breakdown generally corresponds with their more detailed presentation by sub-category. While recognizing that citations and counts of articles are not directly comparable, two areas of apparent difference involve criminology, which accounted for only $2.6 \%$ of the total number of articles analyzed by Schmandt and Wendel (defined as social pathology), and urban/regional economics and economic development, which accounted for about $15 \%$ of the articles they surveyed. In both instances the difference is likely to be explained by the existence of well-established alternative publication outlets.

\section{(Table 5 about here)}

The citation breakdown lends support to a characterization of the discipline along economic and fiscal lines, followed closely by attention to social issues. It could probably be argued that analysis of criminal behavior has risen in relative importance on the social research agenda in recent years at the expense of the earlier emphasis on socio-ecological issues, but this would require more detailed analysis than what is intended here. While it does appear that Raymond's (1989) depiction of the "New Urban Studies" is reflected in the share of citations associated with economic and fiscal analysis, it would not be fair to conclude that social issues no longer capture a significant portion of recognition in the discipline. 


\section{Conclusions}

This paper has provided a ranking of Urban Studies and Urban Affairs graduate programs that serves to update BHB's earlier study. In the course of pursuing this objective some insights were also obtained on the extent to which programs are familiar with each other and on the composition of research contributions. The relatively low level of familiarity with other programs is not a feature one would normally expect in a small discipline, and this finding points to the conclusion that US/UA has not yet developed to a level where its participants identify more closely with each other than with their mother disciplines in the social sciences. The considerable turnover in graduate programs also indicates that the discipline is still very susceptible to changes in program, institutional, and metropolitan environments. Alternatively, it is apparent that US/UA programs have adapted to change and are actively pursuing multi-faceted research, educational, and service objectives. The discipline thus appears well-positioned and possibly better prepared to address the major issues that are likely to dominate the 1990's urban scene. 


\section{$\underline{\text { References }}$}

Bingham, Richard D., Gary T. Henry and John P. Blair, "Urban Affairs Graduate Programs: A Ranking in U.S. Colleges and Universities," Urban Affairs Quarterly, Vol. 16, No. 3 (March 1981), pp. 355-368.

Blair, Dudley W., Rex L. Cottle and Myles S. Wallace, "Faculty Ratings of Major Economics Departments by Citations: An Extension," American Economic Review, Vol. 76, No. 1 (March 1986), pp. 264-267.

Burby, Raymond J. and Edward J. Kaiser, "How Can We Assess the Content of Urban Research?" Urban Affairs Quarterly, Vol. 24, No. 1 (1988), pp. 33-38.

Carson, Richard and Peter Navarro, “A Seller's (\& Buyer's) Guide to the Job Market for Beginning Academic Economists," Journal of Economic Perspectives, Vol. 2, No. 2 (Spring 1988), pp. 137-148.

Cole, Jonathon and Stephen Cole, "Measuring the Quality of Sociological Research: Problems in the Use of the Science Citation Index," American Sociologist, Vol. 6, No. 1 (1971), pp. 23-29.

Davis, Paul and Gustav F. Papanek, "Faculty Ratings of Major Economics Departments by Citations," American Economic Review, Vol. 74, No. 1 (March 1984), pp. 225230.

Gilmore, Jeffrey L., Price and Quality in Higher Education, Washington, D.C., USGPO, October 1990.

Glenn, N.D., "American Sociologists' Evaluation of Sixty-three Journals," American Sociologist, Vol. 6 (1971), pp. 298-303.

Hamilton, David P., "Research Papers: Who's Uncited Now?" Science, Vol. 251 (4 January 1991), p. 25.

Jones, Lyle V., Gardner Lindzey and Porter E. Coggeshall, An Assessment of ResearchDoctorate Programs in the United States: Social and Behavioral Sciences, Washington, D.C., National Academy Press, 1982. 
Kau, James B. and Linda L. Johnson, "Regional Science Programs: A Ranking Based on Publication Performance," Journal of Regional Science, Vol. 23, No. 2 (1983), pp. $177-186$.

Knudsen, D.D. and T.R. Vaughan, "Quality in Graduate Education: An Evaluation of the Rankings in the Cartter Report," American Sociologist, Vol. 4 (1969), pp. 12-19.

Laband, David N., “An Evaluation of 50 'Ranked’ Economics Departments - By Quantity and Quality of Faculty Publications and Graduate Student Placement and Research Success," Southern Economic Journal, Vol. 52, No. 1 (1985), pp. 216-240. Morrill, Richard L., "Productivity of American Ph.D.-Granting Departments of Geography," Professional Geographer, Vol. 32, No. 1 (1980), pp. 85-89. Raymond, Chris, "Once Criticized as Failing to Solve Problems of Cities, Urban Studies Receive Renewed Attention," Chronicle of Higher Education, 6 December 1989. Robey, John S. "Political Science Departments: Reputations Versus Productivity,” PS, Vol. 12, No. 2 (Spring 1979), pp. 202-209.

Roche, Thomas and David Lewis Smith, "Frequency of Citations as Criterion for the Ranking of Departments, Journals, and Individuals," Sociological Inquiry, Vol. 48, No. 1 (1978), pp. 49-57.

Schmandt, Henry J. and George D. Wendel, "Urban Research 1965-1987: A Content Analysis of Urban Affairs Quarterly," Urban Affairs Quarterly, Vol. 24, No. 1 (1988), pp. 3-32.

Stigler, George J. and Claire Friedland, "The Citation Practices of Doctorates in Economics," Journal of Political Economy, Vol. 83, No. 3 (1975), pp. 477-507. Turner, B.L. and William B. Meyer, The Use of Citation Indices in Comparing Geography Programs: An Exploratory Study," Professional Geographer, Vol. 37, No. 3 (1985), pp. 271-278.

Turner, B.L. and William B. Meyer, "Response to Trimble," Professional Geographer, Vol. 39, No. 2 (1987), pp. 203-204. 


\section{Appendix}

US/UA Faculty With 25 or More Citations, 1986-89

\begin{tabular}{|c|c|c|}
\hline & Author and Institution & Citations \\
\hline 1. & Donald Schon, MIT & 490 \\
\hline 2 . & Gordon Clark, Carnegie Mellon & 364 \\
\hline 3 . & Alfred Blumstein, Carnegie Mellon & 358 \\
\hline 4. & Lance Taylor, MIT & 251 \\
\hline 5. & Jerry Miner, Syracuse & 174 \\
\hline 6. & Martin Rein, MIT & 160 \\
\hline 7. & Lester Lave, Carnegie Mellon & 158 \\
\hline 8. & Otto Davis, Carnegie Mellon & 131 \\
\hline 9. & Richard Burkhauser, Syracuse & 131 \\
\hline 10. & Bennett Harrison, MIT & 129 \\
\hline 11. & William Wheaton, MIT & 127 \\
\hline 12. & Robert Warren, Delaware & 119 \\
\hline 13. & John Palmer, Syracuse & 111 \\
\hline 14. & Don Gibbons, Portland State & 105 \\
\hline 15. & James Follain, Syracuse & 101 \\
\hline 16. & Gary Marx, MIT & 95 \\
\hline 17. & Paul Knox, Virginia Tech & 93 \\
\hline 18. & Joan Moore, Wisconsin-Mil. & 88 \\
\hline 19. & Lawrence Susskind, MIT & 87 \\
\hline 20. & John Yinger, Syracuse & 86 \\
\hline 21. & Rajiv Banker, Carnegie Mellon & 79 \\
\hline 22. & Matthew Edel, Queens & 69 \\
\hline 23. & Timothy Smeeding, Syracuse & 68 \\
\hline 24. & Stephen Gottfredson, Temple & 63 \\
\hline 25. & Bernard Frieden, MIT & 56 \\
\hline 26. & Sheldon Krimsky, Tufts & 56 \\
\hline 27. & Richard Hill, Michigan State & 55 \\
\hline 28. & Michael Spicer, Cleveland State & 55 \\
\hline 29. & Jeffrey Berry, Tufts & 55 \\
\hline 30. & Shelby Stewman, Carnegie Mellon & 52 \\
\hline 31. & Vijay Mathur, Cleveland State & 52 \\
\hline 32. & Scott Greer, Wisconsin-Mil. & 48 \\
\hline 33. & Phillip Clay, MIT & 47 \\
\hline 34. & Ashok Dutt, Akron & 44 \\
\hline 35. & Richard Bingham, Cleveland State & 44 \\
\hline 36. & Vernon Greene, Syracuse & 43 \\
\hline 37. & Lawrence Bacow, MIT & 43 \\
\hline 38. & Jacqueline Cohen, Carnegie Mellon & 42 \\
\hline 39. & Mark Haller, Temple & 41 \\
\hline 40. & Stephen Steinberg, Queens & 41 \\
\hline 41. & Judith Tendler, MIT & 39 \\
\hline 42. & Scott Cummings, Louisville & 39 \\
\hline 43. & Terry Buss, Akron & 38 \\
\hline 44. & Franklin Wilson, Wisconsin-Mil. & 38 \\
\hline 45. & Morton Paglin, Portland State & 36 \\
\hline & Harold Rose, Wisconsin-Mil. & 35 \\
\hline & Bert Useem, Louisville & 35 \\
\hline
\end{tabular}


48. Karen Polenske, MIT

49. Michael Gordon, Wisconsin-Mil. 32

50. Barry Cullingworth, Delaware 32

51. Patrick Larkey, Carnegie Mellon 31

52. John Zipp, Wisconsin-Mil. 30

53. Granger Morgan, Carnegie Mellon 30

54. Daniel Nagin, Carnegie Mellon 30

55. Robert Fogelson, MIT 29

56. George Duncan, Carnegie Mellon 28

57. Joel Tarr, Carnegie Mellon 28

58. Carl Abbott, Portland State 28

59. David Morgan, Portland State 28

60. Margo Anderson, Wisconsin-Mil. 27

61. Paul Dommel, Cleveland State 27

62. Ann Greer, Wisconsin-Mil. 26

63. William O'Hare, Louisville 26

64. Timothy Bates, New School 25

65. Richard Florida, Carnegie Mellon 25

66. Victor Greene, Wisconsin-Mil. 25 
Table 1

Peer Ratings of Urban Studies/Urban Affairs Graduate Programs

\begin{tabular}{|c|c|c|c|}
\hline & Program & $\underline{\text { Rating }}$ & Familiarity* \\
\hline 1. & $\overline{\text { Delaware }}^{* *}$ & 8.14 & 60.9 \\
\hline 2. & $\mathrm{MIT}^{* *}$ & 8.11 & 82.6 \\
\hline 3. & Portland State** & 7.50 & 60.9 \\
\hline 4. & Texas, Arlington** & 7.45 & 47.8 \\
\hline 5. & Syracuse $* *$ & 7.36 & 60.9 \\
\hline 6. & Louisville** & 7.27 & 56.5 \\
\hline 7. & Carnegie Mellon** & 7.14 & 60.9 \\
\hline 8. & Cleveland State** & 7.00 & 75.0 \\
\hline 9. & New School & 6.88 & 73.9 \\
\hline 10. & Tufts & 6.87 & 34.8 \\
\hline 11. & Wisconsin, Milwaukee** & 6.60 & 65.2 \\
\hline 12. & Michigan State** & 6.56 & 69.6 \\
\hline 13. & New Orleans & 6.45 & 47.8 \\
\hline 14. & St Louis & 6.44 & 39.1 \\
\hline 15. & Temple & 6.42 & 52.2 \\
\hline 16. & Northeastern Illinois & 6.40 & 21.7 \\
\hline 17. & Georgia State & 6.33 & 65.2 \\
\hline 18. & Virginia Tech & 6.29 & 60.9 \\
\hline 19. & Maryland & 6.21 & 60.9 \\
\hline 20. & Hunter & 6.09 & 47.8 \\
\hline 21. & Akron** & 5.91 & 47.8 \\
\hline 22. & Mankato State & 5.70 & 43.5 \\
\hline 23. & Rensselaer** & 5.67 & 13.0 \\
\hline 24. & Old Dominion & 4.83 & 26.1 \\
\hline 25. & Wright State & 4.80 & 43.5 \\
\hline 26. & Queens & 4.80 & 21.7 \\
\hline 27. & District of Columbia & 4.56 & 39.1 \\
\hline 28. & Montclair State & 4.50 & 8.7 \\
\hline 29. & Long Island, Brooklyn & 4.25 & 17.4 \\
\hline 30. & Trinity & 4.00 & 17.4 \\
\hline 31. & Boston U. & 3.89 & 39.1 \\
\hline 32. & S. Connecticut & 3.00 & 13.0 \\
\hline 33. & Alabama A\&M & 2.33 & 13.0 \\
\hline
\end{tabular}


Table 2

Total and Per Capita Citations, 1986-89

$\frac{\text { Program }}{\text { MrT }}$

Carnegie Mellon

Syracuse

Wisconsin, Mil.

Cleveland State

Temple

Portland State

Delaware

Virginia Tech

Tufts

Queens

Louisville

Akron

Michigan State

New Orleans

New School

Maryland

Texas, Arlington

Hunter

Georgia State

Trinity

Boston U.

St Louis

Rensselaer

Alabama A\&M

Old Dominion

Wright State

Long Island U.

Mankato State

Dist. of Columbia

Montclair State

Northeastern IIl

S. Connecticut
Total

Citations

1492

773

408

282

276

261

190

185

185

159

155

137

135

87

66

63

45

45

45

28

25

22

13

12

10

10

9

8

8

5

5

3
Per Capita

Citations $\quad \underline{\text { Rank }}$ Concentration*

59.96

53.29

45.47

18.54

9.40

12.54

14.50

9.05

10.88

16.82

14.45

7.75

11.41

5.40

6.21

7.33

7.88

11.25

4.09

3.46

7.00

6.25

2.20

4.33

2.00

2.00

3.33

1.12

1.60

2.00

.83

.56

1.50
9.4

7.8

16.1

17.5

9.2

15.5

9.4

4.0

5.9

16.7

11.5

10.6

13.7

6.7

18.4

16.0

19.2

35.8

13.2

18.3

25.0

37.5

8.5

19.7

8.0

25.0

20.8

27.8

20.0

12.5

10.4

9.3

37.5

\footnotetext{
* The smallest percentage of a program's faculty accounting for $50 \%$ of its citations.
} 
Table 3

Composite Ratings of Urban Studies/Urban Affairs Graduate Programs

(z-scores; peer rating/citation weights $=.48 / .52)$

\begin{tabular}{|c|c|c|c|c|c|c|c|}
\hline & Peer & Total & Per Capita & & & & \\
\hline Program & Rating & Citations & Citations & Composite $1^{*}$ & Rank & Composite $2^{* *}$ & $\underline{\text { Rank }}$ \\
\hline MIT & 1.527 & 3.787 & 3.395 & 2.702 & 1 & 2.498 & 1 \\
\hline Carnegie Mellon & .851 & 3.306 & 2.932 & 2.128 & 2 & 1.933 & 2 \\
\hline Syracuse & 1.001 & 1.456 & 2.389 & 1.238 & 3 & 1.723 & 3 \\
\hline Delaware & 1.553 & -.043 & -.138 & .723 & 4 & .674 & 4 \\
\hline Portland State & 1.102 & .139 & .240 & .601 & 5 & .654 & 5 \\
\hline Wisconsin, Mil. & .469 & .517 & .520 & .494 & 6 & .496 & 8 \\
\hline Cleveland State & .750 & .193 & -.114 & .460 & 7 & .301 & 10 \\
\hline Louisville & .939 & -.133 & -.228 & .382 & 8 & .332 & 9 \\
\hline Texas, Arlington & 1.070 & -.416 & .015 & .297 & 9 & .521 & 7 \\
\hline Tufts & .662 & -.056 & .401 & .289 & 10 & .526 & 6 \\
\hline Temple & .340 & .178 & .104 & .256 & 11 & .217 & 11 \\
\hline New School & .668 & -.362 & -.257 & .132 & 12 & .187 & 12 \\
\hline Michigan State & .443 & -.185 & -.391 & .116 & 13 & .009 & 14 \\
\hline Virginia Tech & .248 & -.056 & -.011 & .090 & 14 & .113 & 13 \\
\hline New Orleans & .367 & -.308 & -.335 & .016 & 15 & .002 & 16 \\
\hline St Louis & .360 & -.476 & -.613 & -.075 & 16 & -.146 & 19 \\
\hline Georgia State & .282 & -.416 & -.526 & -.081 & 17 & -.138 & 18 \\
\hline Maryland & .198 & -.370 & -.219 & -.097 & 18 & -.019 & 17 \\
\hline Akron & -.016 & -.180 & .026 & -.101 & 19 & .006 & 15 \\
\hline Northeastern Ill. & .329 & -.519 & -.727 & -.112 & 20 & -.220 & 21 \\
\hline Hunter & .111 & -.416 & -.482 & -.163 & 21 & -.197 & 20 \\
\hline Mankato State & -.163 & -.512 & -.655 & -.344 & 22 & -.419 & 24 \\
\hline Rensselaer & -.187 & -.499 & -.466 & -.349 & 23 & -.332 & 23 \\
\hline Queens & -.796 & -.123 & .237 & -.446 & 24 & -.259 & 22 \\
\hline Old Dominion & -.772 & -.506 & -.627 & -.634 & 25 & -.697 & 26 \\
\hline Wright State & -.796 & -.506 & -.535 & -.645 & 26 & -.660 & 25 \\
\hline District of Columbia & -.968 & -.512 & -.627 & -.731 & 27 & -.791 & 27 \\
\hline Montclair State & -1.007 & -.519 & -.709 & -.753 & 28 & -.852 & 29 \\
\hline Long Island & -1.182 & -.509 & -.688 & -.832 & 29 & -.925 & 31 \\
\hline Trinity & -1.358 & -.460 & -.280 & -.891 & 30 & -.797 & 28 \\
\hline Boston U. & -1.436 & -.468 & -.332 & -.933 & 31 & -.862 & 30 \\
\hline S. Connecticut & -2.061 & -.524 & -.662 & -1.262 & 32 & -1.334 & 32 \\
\hline Alabama A\&M & -2.529 & -.501 & -.627 & -1.474 & 33 & -1.540 & 33 \\
\hline
\end{tabular}

* The weighted sum of the Peer Rating and Total Citation z-scores.

** The weighted sum of the Peer Rating and Per Capita Citation z-scores. 
Table 4

Composite Ratings of Urban Studies/Urban Affairs Programs, by Degree Status (z-scores; peer rating/citation weights $=.39 / .61$ (Ph.D.), .56/.44 (MUS))

\begin{tabular}{|c|c|c|c|c|}
\hline Ph.D. Programs & Composite 1 & $\underline{\text { Rank }}$ & Composite 2 & $\underline{\text { Rank }}$ \\
\hline MIT & 2.906 & 1 & 2.666 & 1 \\
\hline Carnegie Mellon & 2.349 & 2 & 2.120 & 2 \\
\hline Syracuse & 1.279 & 3 & 1.848 & 3 \\
\hline Delaware & .579 & 4 & .521 & 5 \\
\hline Portland State & .515 & 5 & .576 & 4 \\
\hline Wisconsin, Mil. & .498 & 6 & .500 & 6 \\
\hline Cleveland State & .410 & 7 & .223 & 9 \\
\hline Louisville & .285 & 8 & .227 & 8 \\
\hline Texas, Arlington & .164 & 9 & .426 & 7 \\
\hline Michigan State & .060 & 10 & -.066 & 11 \\
\hline Akron & -.116 & 11 & .010 & 10 \\
\hline Rensselaer & -.377 & 12 & -.357 & 12 \\
\hline \multicolumn{5}{|c|}{ MUS/MUA Programs } \\
\hline Tufts & .346 & 1 & .547 & 1 \\
\hline Temple & .269 & 2 & .236 & 3 \\
\hline New School & .215 & 3 & .261 & 2 \\
\hline Virginia Tech & .114 & 4 & .134 & 4 \\
\hline New Orleans & .070 & 5 & .058 & 5 \\
\hline St Louis & -.008 & 6 & -.068 & 7 \\
\hline Georgia State & -.025 & 7 & -.074 & 8 \\
\hline Northeastern 111 . & -.044 & 8 & -.136 & 9 \\
\hline Maryland & -.052 & 9 & .015 & 6 \\
\hline Hunter & -.121 & 10 & -.150 & 10 \\
\hline Mankato State & -.317 & 11 & -.380 & 12 \\
\hline Queens & -.500 & 12 & -.342 & 11 \\
\hline Old Dominion & -.655 & 13 & -.708 & 14 \\
\hline Wright State & -.668 & 14 & -.681 & 13 \\
\hline Dist. of Columbia & -.767 & 15 & -.818 & 15 \\
\hline Montclair State & -.792 & 16 & -.876 & 16 \\
\hline Long Island & -.886 & 17 & -.965 & 19 \\
\hline Trinity & -.963 & 18 & -.884 & 17 \\
\hline Boston U. & -1.010 & 19 & -.950 & 18 \\
\hline S. Connecticut & -1.385 & 20 & -1.445 & 20 \\
\hline Alabama A\&M & -1.637 & 21 & -1.692 & 21 \\
\hline
\end{tabular}


Table 5

Breakdown of Citations by Subject Area

Subject Area

Urban \& Regional Economics; Economic Development

Percent

Urban Social Analysis \& Policy

Criminology \& Criminal Justice

Urban Politics \& Policy

Public Finance \& Management

13

Urbanization, Planning, \& Environmental Policy

12

Urban History

12

8

4 